
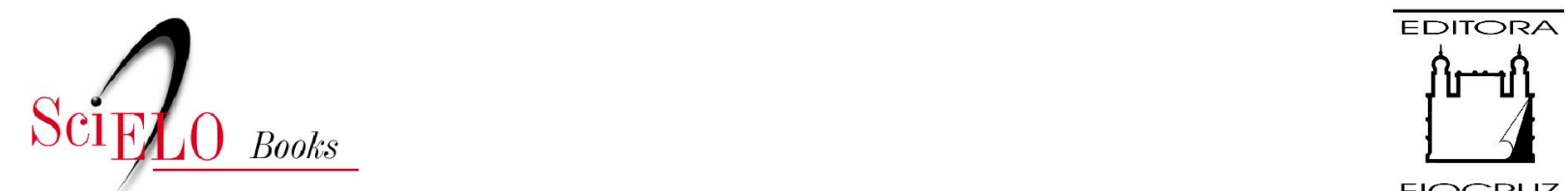

FIOCRUZ

\title{
Alguns aspectos da história da medicina brasileira
}

\author{
Lycurgo de Castro Santos Filho
}

\section{SciELO Books / SciELO Livros / SciELO Libros}

SANTOS FILHO, L.C. Alguns aspectos da história da medicina brasileira. In: MACHADO, M.H., org. Profissões de saúde: uma abordagem sociológica [online]. Rio de Janeiro: Editora FIOCRUZ, 1995, pp. 91-96. ISBN: 978-85-7541-607-5. Available from: doi: 10.7476/9788575416075.006. Also available in ePUB from: http://books.scielo.org/id/t4ksj/epub/machado-9788575416075.epub.

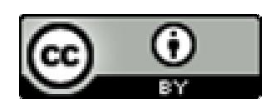

All the contents of this work, except where otherwise noted, is licensed under a Creative Commons Attribution $\underline{4.0 \text { International license. }}$

Todo o conteúdo deste trabalho, exceto quando houver ressalva, é publicado sob a licença Creative Commons Atribição 4.0.

Todo el contenido de esta obra, excepto donde se indique lo contrario, está bajo licencia de la licencia Creative Commons Reconocimento 4.0 . 


\title{
Alguns aspectos da história da medicina brasileira'
}

\author{
Lycurgo de Castro Santos Filho
}

Meus caros companheiros de mesa, caros ouvintes. Vou falar apenas sobre alguns aspectos, porque para falar sobre tudo seria impossível; alguns aspectos da história da medicina, aspectos interessantes.

Quando o Brasil foi descoberto, a patologia reinante era pequeníssima. Pode-se enumerar o bócio ou piã. Sabem o que é bócio, não é? É uma virose que produz bolhas pelo corpo. O bócio endêmico também existente aqui, naturalmente talvez por causa da água iodada, segundo as crenças antigas. Desinteria, algumas doenças, pleuris, pneumonias, doenças inflamatórias, dermatoses e ferimentos (ferimentos de guerra, ferimentos de acidente, e tal), e mais nada.

Começa a civilização, e vem o negro e vem o branco. O negro traz uma patologia riquíssima da África: é a dracunculose, é o gundu, o ainhum, a filariose, enfim, inunda-se o país de doenças africanas. Basta que os séculos corram e não havendo mais o vetor, essas doenças foram por si desaparecendo.

O maculo por exemplo, para dar uma amostra interessante, era o Mal de Culo. Consistia, sabemos hoje, numa retite infriltrativa, ulcerante, complicada pela míase. O ânus ficava exposto, cheio de gusanos. Então, inventaram um tratamento que é uma verdadeira barbaridade. Punham o paciente de cabeça para baixo, encostado na parede, seguro por duas pessoas, abriam as pernas e dentro do ânus enfiavam o que se chamava "saca-trapo", uma massa de pimenta, vinagre, verdete, tabaco, tudo o que pudesse ser irritante. Enfiavam, fechavam as pernas e as amarravam, e deixavam o coitado sofrendo por umas duas horas.

O holandês Guilherme Pizo, no livro que escreveu sobre a medicina brasiliense, descreveu a doença, o maculo; e disse que o tratamento

1 Transcrição revista da gravação da conferência proferida no seminário Medicina no Brasil: perspectivas históricas e sociológicas, em 14 de outubro de 1992, no Salão Internacional da Escola Nacional de Saúde Pública da Fundação Oswaldo Cruz. 
seria facílimo: lavar com água do mar. Seria um tratamento higiênico, preventivo.

Vejam bem, um negro trabalhando no eito, com a foice, sem poder largá-la. Vinha a vontade de obrar e ele defecava ali mesmo no campo; não se limpava. Resultado, vinham as moscas e se instalavam no ânus, provocando a ulceração que chamaram de Mal de Culo, tema de um dos primeiros livros da bibliografia nacional.

Depois das doenças dos negros, ou concomitantementes, vieram as doenças dos brancos trazidas da Europa: tuberculose, lepra (diziam que talvez existisse nas Antilhas, mas não está nada provado), e outras doenças. Essas e as outras doenças compõem a patologia moderna. Vieram trazidas pelos brancos, principalmente a tuberculose, a varíola, a febre amarela. Essas doenças provocaram verdadeiras epidemias, pois não havia entre os indígenas aquela imunidade adquirida em gerações. E eles, que somariam no início cinco milhões, chegaram ao século XIX reduzidos a 200 mil.

A primeira epidemia de febre amarela, em Salvador da Bahia, matou o capitão-general do Brasil, o arcebispo de Salvador, três desembargadores, oito jesuítas; enfim, fez uma razia na cidade. Era uma epidemia que afinal extingui-se, cessou, para voltar só no fim do século XIX e tornar-se endêmica. Todos sabemos da ação de Oswaldo Cruz contra a febre amarela.

O Brasil, que antes era uma terra de poucas doenças, tornou-se até um país mal afamado. Havia na Europa, nos portos de embarque para a América do Sul, avisos assim: "Este navio não tocará em portos do Brasil".

$E$ que foram e quais foram os profissionais que aqui exerceram a medicina? Os que vieram no século XVI e também no século XVII eram todos cristãos novos, filhos de um pai (ou mãe) cristão e judeu. Eles vinham fugidos, vinham para escapar da inquisição que já estava instalada em Portugal, e aqui se espalharam pelas povoações do litoral e também em algumas do interior.

E que medicina era essa que eles exerceram? A mais rudimentar possível, de poucos conhecimentos, levando o arcebispo do Pará, D. Frei Caetano Brandão, a dizer no século XVIII: "É preferível a gente tratar-se com um tapuia do sertão do que com um médico de Coimbra." E por que? Porque o tapuia do sertão observa com melhor instinto.

Mas esses cristãos novos, esses que se constituíram nos profissionais daqui, eu consegui descrevê-los aproveitando trechos de livros que publicaram. As confissões e denúncias ao Santo Ofício no Brasil foram a 
minha principal fonte com os melhores e maiores informes. Os denunciados já haviam morrido.

Havia um famoso vigário em Matoim, no final do século XVI, que era um terrível bissexual, mantinha relações pelo vaso traseiro e pelo vaso dianteiro. Pois bem, esse compareceu ao Tribunal e era pároco de Matoim, perto de Salvador.

E assim, então, pelas confissões e denúncias, ficaram conhecidos todos os pormenores da vida dos cristãos novos, que não se fixavam por muito tempo num só lugar, viviam como ambulantes, mudando de local com grande freqüência, nos séculos XVI e XVII.

Já no século XVIII, surgiram funcionários melhores, de melhor instrução. Eram os formados em Salamancra e em Coimbra, os licenciados, físicos e cirurgiões.

Médico em inglês é physician, e o físico então era um médico. Os que vieram para a colônia conheciam os medicamentos da Europa, desconhecendo os daqui. Tiveram então que estudá-los. Por quê? Porque os que traziam se esgotavam num instante. Então, foram descobertas as propriedades terapêuticas dos vegetais brasileiros, a partir do século XVII. E para esse conhecimento muito contribuiu o padre jesuíta, que indagava do indígena o que ele estava tomando, o que ele estava fazendo, o que o pajé etc. E assim, os jesuítas foram descobrindo as virtudes da ipecacuanha e de medicamentos como a copaíba. O óleo de copaíba é até hoje usado.

Quais são, no século XIX, os profissionais da medicina no Brasil? São os doutores formados nas faculdades do Rio de Janeiro e da Bahia, que defendiam tese e possuíam orientação francesa. Os compêndios eram todos em francês. Muitos dos aqui formados iam para a Europa para se aperfeiçoarem.

Assim tivemos ótimos médicos que não deixaram, entretanto, de incorrer em muitos equívocos, como por exemplo, o grande Tôrres Homem, professor da Faculdade de Medicina do Rio de Janeiro. Ele publicou um livro sobre as febres, onde defendeu em páginas e páginas uma síndrome que seria a "tifo-malárica". E assim, como essa, muitas outras, vamos dizer, impropriedades.

O meu avô era médico e residia em Guaratinguetá. Pois publicou, em 1882, um artigo sobre a tuberculose, dizendo que não era contagiosa. E ele já estava tuberculoso! Daí uns quinze dias recebeu jornais da Corte, que era no Rio de Janeiro, noticiando que na Alemanha, Robert Cocke havia descoberto o bacilo da tuberculose. Ele imediatamente enviou um artigo dizendo: "Tenho que me penitenciar pelo que escrevi dizendo que 
a tuberculose não era contagiosa. Ela é contagiosa, de acordo com o qu acaba de ser divulgado pelo sábio Robert Cocke."

Vejam o que era a incipiente ciência que veio desaguar no século XX. A cirurgia da época consistia em lancetar, abrir os abcessos, amputar e desarticular. Era nisso que se cifrava a cirurgia durante os 400 anos de colonização, depois da descoberta do Brasil. Os ferros cirúrgicos cabiam num pequeno estojo. Eu possuo o estojo de cirurgia adquirido pelo meu bisavô, que era médico. Ele saiu do Rio de Janeiro em navio à vela, porque a passagem era mais barata do que em navio movido à máquina. Foi para Paris para adquirir um estojo de cirurgia e trouxe esse estojo que servia (Pasteur ainda não havia descoberto os micróbios) tanto para fazer uma operação quanto para fazer uma autópsia ordenada pelo delegado de polícia. Como ele era um indivíduo de costumes higiênicos, costumava lavar os ferros com água e sabão, mas não podia ferver pois os cabos eram de madeira. O ferro, sim, era puro aço Charrier.

Este livro aqui, que ora eu mostro, apresenta aspectos da história da medicina na América Latina e foi editado em Nova York. Traz no meu artigo, que apresentei na comunicação, o estojo aberto. Acharam interessantíssimo. O estojo fechava com apliques dourados.

A primeira operação de ligadura da aorta abdominal no Brasil foi a quarta no mundo. O Visconde de Itaúna, professor Cândido Borges Monteiro, sabendo que em Londres tinham sido feitas três operações de ligadura da aorta abdominal mandou vir as publicações e repetiu a cirurgia. Apesar do êxito cirúrgico, morreram os pacientes.

No caso de aneurisma da artéria aorta primitiva, ele usou a mesma técnica de Joe Mourrih, em Londres. Era o ano de 1842, e o paciente de Mourrih morreu no $12^{\circ}$ dia do pós-operatório. Por quê? Porque supurou a ferida operatória, lacerou a sutura e deu-se a hemorragia da aorta.

A mesma coisa aconteceu no Rio de Janeiro com o Visconde de Itaúna: o seu paciente foi operado, passou muito bem, até que no $12^{\circ}$ dia morreu. Ele fez a autópsia. Havia sido também por soltura do categute. Essa operação foi comemorada por Augusto Brandão Filho. Em 1942 mandou imprimir, à custa própria, uma medalha com a efígie do Visconde de Itaúna numa face e na outra gravou: "Centenário da Operação da ligadura da Aorta Abdominal". Tivemos, então, médicos competentes, mas que naturalmente sofreram as deficiências da época.

Esses ferros que estão aí sendo mostrados serviram para operar a minha bisavó. O marido dela, José Manuel de Castro Santos, foi quem comprou os ferros em Paris. Certo dia ela disse que estava com um "ca- 
rocinho". Ele respondeu: "Minha mulher, isso é um cancro", como se dizia antigamente e até há pouco tempo. Quando cursei a faculdade aprendi que não se falava câncer, mas cancro. "Vai ter que tirar", disse à mulher. Foi ela sentada numa cadeira da sala de jantar da chácara, amarrada. Deram um naco de tabaco para mascar. Ela não quis anestesia, que já existia, com a máscara de Ombredane. Havia visto muitos pacientes do marido morrerem da anestesia. Ela disse: "Não, eu não quero não, vai sem anestesia mesmo". Bem, logo nos primeiros cortes, ela desmaiou; aí pôde ser feita a operação. Eu vim a conhecê-la, morreu com cem anos de idade em 1921. E o marido morreu cinco ou seis anos depois que havia operado a mulher.

Apareceu no Rio de Janeiro o Dr. José Francisco Xavier Sigaud, médico francês que aí exerceu a profissão e aí veio a falecer em 1856. Publicou ele o livro Du climat et des maladies du Brèsil (Paris, 1844), livro que pode ser comparado a qualquer tratado de patologia europeu. Foi ele, no Rio de Janeiro, o primeiro diretor do Imperial Instituto dos Meninos Cegos. Nesse livro de Sigaud encontrou-se toda a patologia da época, e principalmente aquela vigente no Brasil. É uma fonte documentária muito boa.

No século XIX surgiram as faculdades de medicina da Bahia e do Rio de Janeiro. Por estar longe da Corte, a escola da Bahia não tinha as mesmas condições que a Faculdade de Medicina do Rio de Janeiro.

Casos interessantes aconteceram aqui em matéria de medicina. Por exemplo, o tratamento da lepra pelo veneno da cascavel foi um verdadeiro acontecimento no Rio de Janeiro. OJornal do Commercio da época, meados do século XIX, descreveu a cena: havia sessenta pessoas na casa do leproso. O Dr. Jacinto Pereira Reis, notável médico do Rio de Janeiro, mandou vir uma gaiola com uma cascavel e fez com que o doente enfiasse a mão dentro da gaiola. Sabem o que aconteceu? A cobra se enrodilhava toda, não queria picar, foi preciso espicaçá-la do lado de fora da gaiola para ela então dar uma mordida. Vinte e quatro horas depois o homem morreu.

Um outro caso muito interessante foi o do Dr. Antônio José Peixoto, um dos maiores médicos do Rio de Janeiro, que possuía Casa de Saúde, a primeira Casa de Saúde. Ele tinha a mania de namorar francesas, era casado com uma francesa e mantinha duas amantes também francesas. Eis que surgiu, no Rio, Amelinha Melgi, uma atriz que viera com o marido, componentes de uma companhia de artistas. E Peixoto, naturalmente, achou-a muito bonitinha e namorou-a. Ela foi vista entrando e saindo 
do consultório de Peixoto várias vezes. Naturalmente mantiveram relações sexuais. Contaram ao marido e este matou-a. Foi a julgamento e o júri o absolveu. Foi carregado em triunfo por populares das Ruas da Quitanda e do Ouvidor. Peixoto, quietinho, nada comentou.

Afinal, um dia ele subornou o guardião do Convento de Santo Antônio, onde estava enterrada a francesinha, retirou o cadáver e levou-o para o consultório, à noite. Foi ajudado, diziam na época, pelo futuro Barão de Teresópolis, Francisco Ferreira de Abreu, professor da Faculdade de Medicina. Pesquisei o assunto e concluí que o Barão de Teresópolis nada teve a ver com a trama.

Peixoto colocou o corpo dentro de um caldeirão. Conseguiu limpar todos os ossos, armou o esqueleto e colocou-o no consultório. Populares deram queixa à polícia e, interrogado, o médico disse que o esqueleto era da francesinha mesmo e que iria enviá-lo para Paris, onde morava a mãe da atriz. E, de fato, acondicionou os ossos e no primeiro navio despachou-os para Paris. No navio seguinte, seguiu para Paris. Lá chegando, foi à alfândega. Os ossos não tinham sido reclamados pela mãe da mocinha. Ele reclamou-os como um membro da família. Pegou os ossos e... enterrou-os num cemitério.

E aqui encerro a exposição. Espero que tenham apreciado. Se quiserem fazer alguma pergunta, estou à disposição. 